\title{
Possibilities for Misinterpretation in ASV-Speciation Studies of Natural Waters*
}

\author{
Cees J. M. Kramer, Yu Guo-hui ${ }^{1}$, and Jan C. Duinker ${ }^{2}$ \\ Netherlands Institute for Sea Research P.O. Box 59, Texel, The Netherlands
}

\section{Mögliche Mißdeutungen bei ASV-Speciesuntersuchungen von natïrlichen Wässern}

Zusammenfassung. Die Probleme, die bei Speciesuntersuchungen von Spurenelementen mit Hilfe der Differentialpuls Anodic Stripping Voltammetrie auftreten, werden zusammenfassend dargestellt. Neben den bei der eigentlichen Bestimmung auftretenden Problemen, werden auch solche erwähnt, die mit der Probennahme sowie der Lagerung und Vorbehandlung der Proben in Zusammenhang stehen.

Summary. A summary is given of possible pitfalls identified in the speciation studies of trace elements by Differential Pulse Anodic Stripping Voltammetry including sampling-, storageand sample treatment procedures.

\section{Introduction}

Speciation studies of trace elements are essential for understanding their bioavailability, adsorption/desorption characteristics and transport mechanisms (involving e.g. ionic forms, (in)organic complexes, colloids). The problems associated with the use of special techniques required for speciation studies at extremely low concentration levels, are more severe than when dealing with mere total concentration determinations. Some problems in speciation studies will be summarized here. They refer to sampling-, storage- and sample treatment procedures, in relation to analytical determination by Anodic Stripping Voltammetry (ASV).

\section{Problems Associated with Sampling-, Storage- and Sample Treatment Procedures}

Sampling. Extreme precautions and special equipment are required for total trace element concentration determination in natural waters $[1,2]$. In addition, distinction of different species may cause problems, e.g. due to the release of organic compounds [3], some of which may change speciation. Clean room or at least clean bench facilities are essential for minimizing or preferably preventing sample contamination [4].

\footnotetext{
* Dedicated to Prof. Dr. W. Fresenius on the occasion of his 70th birthday

1 Present address: 2nd Institue of Oceanography, Hangzhou, Peoples Republic of China

2 Present address: Institut für Meereskunde, Düsternbrooker Weg 20, D-2300 Kiel, Federal Republic of Germany

Offprint requests to: C. J. M. Kramer
}

Filtration. Filtration results in operationally defined 'dissolved' and 'particulate suspended' fractions. Colloids can play an important role in complexation processes. They are able to pass a filter (usually $0.45 \mu \mathrm{m}$ Nuclepore or Millipore). However, they can be removed by ultrafiltration, following $0.45 \mu \mathrm{m}$ pore size filtration. Thus, a better estimate is obtained of 'truly dissolved' $(<0.001 \mu \mathrm{m})$ forms [5]. All steps in these procedures are likely sources of contamination, however.

Storage. During storage, existing equilibria may be affected. This risk is minimized by analysis of the sample as soon as possible after sampling. If necessary, samples should be stored at $4^{\circ} \mathrm{C}$ in the dark. This is less likely to change the sample irreversibly than deepfreezing [6].

Pretreatment of Samples. The aim of speciation studies is to gain insight into the qualitative and quantitative aspects related to the different species present in a sample. Addition of chemicals needed for analytical determinations will, in principle, change these aspects.

Thus, the sample should not be acidified, nor should buffer, supporting electrolyte (for ASV measurements), mercury ions (for MFE formation) or any other chemical be added.

\section{DPASV Analysis in Speciation Studies}

Problems are also met in the final step of the analytical procedure, i.e. the determination of total concentration or the distinction and separate analysis of different species e.g. by (Differential Pulse) Anodic Stripping Voltammetry. Some of them will be discussed in the following section.

Determination of low trace metal concentrations in natural samples requires a technique with extreme sensitivity, such as Differential Pulse Anodic Stripping Voltammetry (DPASV), which has the additional advantage that distinction of different species even at extremely low concentration levels in natural waters is possible for some trace elements. The HMDE has the advantage that the electrode surface is renewed for each measurement, but it suffers from relatively low sensitivity. Thin mercury film electrodes have strongly increased sensitivities. They can be applied with a preformed film or with an in-situ formed film. Although the latter type has a higher sensitivity, it cannot be used in speciation studies because $\mathrm{Hg}(\mathrm{II})$ ions added to the solution to be analysed, change existing equilibria. The preformed jet-stream electrode (JMFE) as described in [7] proves to be more sensitive than the RMFE (Table 1). 
Table 1. Comparison of hanging mercury drop electrode (HMDE), rotating mercury film electrodes (RMFE, in-situ and preformed) and the jet-stream mercury film electrode (JMFE) with respect to copper peak potential $\left(E_{\mathrm{p}}\right.$ in $\left.\mathrm{mV}\right)$, peak width at half-height $\left(b_{1 / 2}\right.$ in $\left.\mathrm{mV}\right)$ and sensitivity in $\mathrm{A} \mathrm{mol}^{-1} \mathrm{dm}^{3} \mathrm{Cu}(\mathrm{II})$. All deposition times were $180 \mathrm{~s}$ : the film electrodes $(6 \mathrm{~mm}$ diameter $)$ were used under optimum conditions

\begin{tabular}{llcc}
\hline Electrode type & $E_{\mathrm{p}}(\mathrm{mV})$ & $b_{1 / 2}(\mathrm{mV})$ & $\begin{array}{l}\text { Sensitivity } \\
\left(\mathrm{A} \mathrm{mol}{ }^{-1} \mathrm{dm}^{3}\right) \\
\text { for Cu(II) }\end{array}$ \\
\hline HMDE & -110 & 90 & 2 \\
RMFE in-situ & -260 & 45 & 108 \\
RMFE preformed & -270 & 70 & 57 \\
JMFE preformed & -290 & 70 & 254 \\
\hline
\end{tabular}

DPASV is often used in speciation studies for the distinction, at the natural $\mathrm{pH}$, of so-called labile and nonlabile species and also for the determination of the complexation capacity $(\mathrm{CC})$ for a specific element. This parameter indicates the amount of ionic metal that can be taken up into non-labile complexes by (organic) ligands present in the natural sample. It can be determined by titration of the ligands with ionic copper, and careful analysis of the data $[5,8,9]$.

Several problems can be identified in these procedures.

Adsorption to the Cell. In the absence of possible ligands which are able to form non-labile complexes, the relation between ASV response and concentration of metal added to the solution, is expected to be linear. However, the presence of ligands may result in deviations from linearity. It has been found that such observations can also result from adsorption to the cell wall [10].

Adsorption onto Electrodes. The adsorption of organic matter on the mercury electrode surface is a common problem and is often discussed in the literature. It may result in a shift in the peak potential, broadening of the peaks, in additional and usually sharp peaks at more positive potentials, decreased sensitivity or in non-linear calibration relations.

Organic matter may also influence the behaviour of the platinum counter electrode. Especially in low salinity waters with a high organic matter content, organic matter is easily adsorbed onto the Pt surface. As a consequence, the electrode is shielded and sensitivity decreases. The effects get more serious in consecutive measurements of the $\mathrm{CC}$ determination. The adsorbed organics can be observed usually as a yellow film covering the platinum coil.

Adsorption During Equilibration. If the $\mathrm{CC}$ measurements are carried out in the equilibration method, where several individual sample aliquots are spiked with different concentrations of copper for equilibration during e.g. $24 \mathrm{~h}$ prior to analysis [5], adsorption to the walls of the flasks may influence the $\mathrm{CC}$ determinations.

Formation of the Mercury Film. The preformed mercury film electrode may show non-linear response, if inappropriate film formation procedures have been applied.

Experimental conditions during film formation [related to e.g. $\mathrm{Hg}(\mathrm{II})$ concentration and deposition time] determine the characteristics of the MFE. An optimum film has a linear calibration curve and has maximum sensitivity. A film that is too thin has decreased sensitivity; a film that is too thick (resulting from high mercury concentrations or long deposition times) adversily affects the calibration curve [11]. The resulting curve may then suggest complexation of added trace elements, in cases where the similarity to complexing capacity properties is in fact due to erroneous electrode characteristics. It can be checked and cured by simple experiments [11].

Conditioning of the MFE. The parameters controlling conditioning of the MFE before and between measurements should also be optimized, in order to avoid memory effects or non-constant electrode behaviour.

$p H$ Control. Purging a water sample with nitrogen results in a $\mathrm{pH}$ increase. Existing equilibria and speciation measurements are then likely to be affected. The use of a $\mathrm{pH}$-stat using $\mathrm{CO}_{2}$ as reagent is recommended [12], rather than the use of buffers for reasons mentioned before.

Complexation Kinetics. Slow reactions may result in slow approach of equilibrium in the complexation reactions after spiking the sample with copper. Then, $\mathrm{CC}$ will be underestimated. These problems can be eliminated by application of Ruzic's method [13].

Reaction with Colloids. Inorganic and/or organic colloidal material that passes a $0.45 \mu \mathrm{m}$ filter, or flocculates precipitates formed after filtration, may react with the $\mathrm{Cu}^{2+}$ (adsorption, complexation) influencing the determination of complexing capacity.

Intermetallic Compounds. The formation of $\mathrm{Cu}-\mathrm{Zn}$ intermetallic compounds in the mercury electrode has been reported as cause for non-linearity in CC titration curves [14]. At the low concentrations, used in the CC determinations of natural samples for trace metals, no intermetallic compounds are expected to occur. The suggestion of these authors is probably based on incorrect observations as the applied deposition potential $(-700 \mathrm{mV})$ was not sufficiently negative to reduce zinc.

Most effects mentioned above might be avoided by carefully establishing optimum conditions of the measurements, e.g. choice of materials, cleaning procedures, electrode handling, equilibration, $\mathrm{pH}$ control and electrochemical parameters.

\section{References}

1. Mart L (1979) Fresenius Z Anal Chem 299:97-102

2. Patterson CC, Settle DM (1976) In: LaFleur PD (ed) Accuracy in trace analysis: Sampling, sample handling and analysis. NBS Spec Publ 422:321 - 351

3. Zsolnay A (1978) Mar Poll Bull 9:23-24

4. Mart L (1979) Fresenius Z Anal Chem 296:350-356

5. Kramer CJM (1984) In: Complexation of trace metals in natural waters. Martinus Nijhoff/dr W Junk Publ, Den Haag (in prep)

6. Batley GE, Florence TM (1976) Marine Chem 4:347-363

7. Magjer T, Branica M (1977) Croatica Chim Acta 49:L1-L5

8. Hart BT (1981) Environ Technol Lett 2:95-110

9. Neubecker TA, Allen HE (1983) Water Res 17:1-14

10. Zirino A, Kounaves SP (1980) Anal Chim Acta 113:79-90

11. Yu Guo-hui, Kramer CJM, Duinker JC (1984) In: Complexation of trace metals in natural waters. Martinus Nijhoff/dr W Junk Publ, Den Haag (in prep)

12. Kramer CJM, Manshanden GM (1982) Internal NIOZ report 1982-4 Texel, The Netherlands

13. Ruzic I (1982) Anal Chim Acta 140:99-113

14. Lazar B, Katz A, Ben-Yakov S (1981) Marine Chem 10:221-231

Received October 5, 1983 